\title{
Should ESGE implement optical diagnosis in Europe?
}

\section{다)(1) $(-)$}

\author{
Authors \\ C. Hassan ${ }^{1}$, T. Ponchon ${ }^{2}$ \\ Institutions \\ 1 Endoscopy Unit, Nuovo Regina Margherita Hospital, \\ Rome, Italy \\ 2 Gastroenterology and Endoscopy, Edouard Herriot \\ Hospital, Lyon, France \\ Bibliography \\ DOI https://doi.org/10.1055/s-0043-118002 | \\ Endoscopy International Open 2017; 05: E1208-E1210
}

\author{
(c) Georg Thieme Verlag KG Stuttgart · New York \\ ISSN 2364-3722 \\ Corresponding author \\ Cesare Hassan, MD, Nuovo Regina Margherita, \\ Via Morosini 30, 00153 Roma, Italia \\ Fax: +39065844-6533 \\ cesareh@hotmail.com
}

It is not the scientific relevance of endoscopic innovations per se that justifies an endorsement by an international society of endoscopy. Indeed, most innovations represent mere improvements in already established practices. On the other hand, when endoscopic innovations dramatically change the current standard of care - and risking uncertainty about the potential benefit and risks - that a scientific society should be expected to express its perspective about these advances.

The latter is clearly the case for new clinical strategies based on application of optical diagnosis of polyps $\leq 5 \mathrm{~mm}$ detected at colonoscopy. According to the "resect and discard" (R\&D) strategy, all colorectal polyps $\leq 5 \mathrm{~mm}$ in vivo characterized with high confidence as either adenomatous or hyperplastic do not require post-polypectomy histological examination. In addition, as already widely accepted in clinical practice, recto-sigmoid polyps $\leq 5 \mathrm{~mm}$ characterized as hyperplastic by optimal diagnosis can be left in place.

Is it the right time for the European Society of Gastrointestinal Endoscopy (ESGE) to support the clinical implementation of optical diagnosis for diminutive polyps? First, these strategies find their main field of application in settings of clinical relevance, such as ongoing colorectal cancer (CRC) screening programs that aim to reduce the second leading cause of cancer-related morbidity and mortality in Europe. Second, the technological innovation on which the R\&D strategy is based (i. e., Narrow Band Imaging, Blue Light Imaging, I-scan) is widely available in European endoscopy centers, so any delay would be hard to justify. Third, the scientific community appropriately updated the standard of care by creating and validating dedicated classifications for optical diagnosis. The NBI International Colorectal Endoscopic (NICE) represents a successful compromise between Western and Japanese perspectives, resulting in a clear differentiation between hyperplastic and adenomatous polyps, as well as accurate prediction of deeply invasive cancer $[1,2]$. In addition, the recent Workgroup serrAted polypS and Polyposis (WASP) classification showed promising accuracy for optical diagnosis of sessile serrated polyps [3]. Fourth, a large amount of data mainly coming from tertiary centers successfully validated the clinical efficacy of the R\&D strategy, based on both the intrinsic high accuracy of optical diagnosis and fulfillment of the PIVI set by the American Society for Gastrointestinal Endoscopy [4, 5].

Decision-making by any scientific society should be driven by exploitation of a widely accepted and objective methodology. ESGE recently embraced GRADE as the most suitable methodology for clinical decisions [6]. According to GRADE, the choice between "to recommend" or "to recommend against" a clinical intervention should be based on an objective comparison between benefit on one side and risks and burden - both economic and financial - on the other[6].

What are the main benefits and risks (burden) of the R\&D strategy? Saving the histological costs associated with $\leq 5 \mathrm{~mm}$ polyps is by far the most relevant benefit. While already accounting for over $80 \%$ of diagnosed lesions [7], detection of polyps $\leq 5 \mathrm{~mm}$ is likely to further increase due to current recommendations to boost the adenoma detection rate of individual endoscopists $[8,9]$. A second benefit is the possibility of immediately assigning appropriate post-polypectomy surveillance after colonoscopy in most cases, marginalizing the burden of a second visit after histology to those relatively few patients with polyps $\geq 5 \mathrm{~mm}$.

On the other hand, the main drawback of R\&D strategy is clearly represented by the fear of inappropriately delaying surveillance due to misinterpretation of an adenoma as a hyperplastic polyp (i.e., a false-negative optical diagnosis). However, such risk strictly depends on stratification adopted within the reference guidelines for post-polypectomy surveillance. In detail, ESGE recommends return to screening or 10-year colonoscopy in those without advanced neoplasia, irrespective of 
whether a lesion $<10 \mathrm{~mm}$ is a non-advanced adenoma or hyperplastic [10]. Thus, such a recommendation marginalizes any risk associated with potential false-negative optical diagnosis. That differs from American guidelines, which recommends offering patients with non-advanced adenomas 5 - to 10 -year surveillance versus the somewhat delayed 10 -year interval in those with hyperplastic polyps [11]. It could be argued that an additional risk is represented by those very few patients who harbor an advanced histology within a lesion $\leq 5 \mathrm{~mm}$, as optical diagnosis is likely to be ineffective in discriminating between advanced and non-advanced adenomas $\leq 5 \mathrm{~mm}$. Three-year surveillance would, indeed, be warranted in those patients according to both ESGE and American guidelines rather than the 10year interval that would be assigned based on an apparently correct optical diagnosis strategy $[10,11]$. However, the actual rate of advanced neoplasia (i. e., high-grade dysplasia, villosity) is very low in diminutive adenomas, where the risk of invasive cancer is, if any, exceptionally rare $[12,13]$. In addition, there is some evidence that risk of metachronous advanced neoplasia in patients stratified as high risk due to diminutive polyps is actually very low.

In a cost-effective simulation model published in this issue of this journal, Vleugels J et al. were able to compare the potential benefit of the R\&D strategy - mainly its economic saving - with all the potential sources of risks, including the loss of life-years due to inappropriately delayed surveillance in patients at high risk due to advanced adenomatous or serrated neoplasia within a polyp $\leq 5 \mathrm{~mm}$ [14]. The Authors succeeded in showing the cost-saving profile of the R\&D strategy, while excluding any loss in life expectancy coupled with it [14]. These findings are critically relevant for implementation of a R\&D strategy. First, the cost-saving profile was shown in a simulated program with an immunochemical fecal test that represents the predominant scenario in Europe. This excludes any detrimental effect of implementation of optical diagnosis in ongoing programs. Second, it is the first model that takes into account the possibility of sessile serrate polyp within polyps $\leq 5 \mathrm{~mm}$. Third, unlike previous models [15, 16], Vleugels ] et al. actually based their simulation on accuracy data computed in non-tertiary centers, ensuring the generalizability and reproducibility of the study outcomes [14]. Fourth, the results of the model were confirmed when adopting ESGE versus Dutch guidelines, showing a relative independence from the selected setting [7].

When considering the favorable data from Vleugels J et al., should ESGE call for an immediate and indiscriminate application of the R\&D strategy based on optical diagnosis? Despite the unequivocal validity of this model, there are still major barriers that must be addressed before widespread implementation of the R\&D strategy is allowed. First, when discarding a polyp, no post-polypectomy specimen is actually collected. Thus, photodocumentation must replace pathology storage both for clinical and legal reasons. Additional evolution of endoscopic databases may be required to ensure long-term maintenance of this relevant documentation. Second, the unexpectedly suboptimal performance shown when implementing optical diagnosis by community-based endoscopists underscores the need for both training and auditing [17]. Of note, most training in optical di- agnosis can be conveniently performed with interactive tools that are shown to be extremely effective in non-expert settings [18]. Education and training represent the core ESGE mission. Thus, ESGE can be expected to perform an active role in implementing such training, and to play a persuasive role in convincing national societies to activate a formal process for monitoring, certification, and auditing.

In 2014, ESGE was the first scientific society to officially give a (weak) recommendation for implementation of R\&D strategy in clinical practice [19], pending fulfillment of unequivocal criteria, namely: 'the optical diagnosis has to be reported using validated scales, must be adequately photo-documented, and can be performed only by experienced endoscopists who are adequately trained and audited.' [19]

ESGE's position on R\&D very recently was adopted by the National Institute for Health and Care Excellence, which also supported its clinical implementation pending conditions very similar to those required by ESGE [20]. These societies did their best to indicate what the new standard of care is to be. It is time now for the endoscopy community to show their commitment to being trained in and audited on optical diagnosis, in order to implement R\&D strategy in clinical practice. What may appear to be a relatively small step for endoscopy may become a huge savings for society!

\section{Competing interests}

None

\section{References}

[1] Hewett DG, Kaltenbach T, Sano Y et al. Validation of a simple classification system for endoscopic diagnosis of small colorectal polyps using narrow-band imaging. Gastroenterology 2012; 143: 599-607 e591

[2] Hayashi N, Tanaka S, Hewett DG et al. Endoscopic prediction of deep submucosal invasive carcinoma: validation of the narrow-band imaging international colorectal endoscopic (NICE) classification. Gastrointestinal Endosc 2013; 78: 625-632

[3] IJspeert JE, Bastiaansen BA, van Leerdam ME et al. Development and validation of the WASP classification system for optical diagnosis of adenomas, hyperplastic polyps and sessile serrated adenomas/ polyps. Gut 2016; 65: $963-790$

[4] Wanders LK, East JE, Uitentuis SE et al. Diagnostic performance of narrowed spectrum endoscopy, autofluorescence imaging, and confocal laser endomicroscopy for optical diagnosis of colonic polyps: a meta-analysis. Lancet Oncol 2013; 14: 1337-1347

[5] Rex DK, Kahi C, O'Brien M et al. The American Society for Gastrointestinal Endoscopy PIVI (Preservation and Incorporation of Valuable Endoscopic Innovations) on real-time endoscopic assessment of the histology of diminutive colorectal polyps. Gastrointestinal Endosc 2011; 73: 419-422

[6] Dumonceau JM, Hassan C, Riphaus A et al. European Society of Gastrointestinal Endoscopy (ESGE) Guideline Development Policy. Endoscopy 2012; 44: 626-629

[7] Rex DK, Helbig CC. High yields of small and flat adenomas with highdefinition colonoscopes using either white light or narrow band imaging. Gastroenterology 2007; 133: $42-47$ 
[8] Kaminski MF, Thomas-Gibson S, Bugajski M et al. Performance measures for lower gastrointestinal endoscopy: a European Society of Gastrointestinal Endoscopy (ESGE) quality improvement initiative. United Europ Gastroenterol J 2017; 5: 309-334

[9] Hassan C, Repici A. Defeating Cancer by Boosting the Adenoma Detection Rate: The Circle of Life. Gastroenterology 2017; 153: 8-10

[10] Hassan C, Quintero E, Dumonceau JM et al. Post-polypectomy colonoscopy surveillance: European Society of Gastrointestinal Endoscopy (ESGE) Guideline. Endoscopy 2013; 45: 842 - 851

[11] Lieberman DA, Rex DK, Winawer S] et al. Guidelines for colonoscopy surveillance after screening and polypectomy: a consensus update by the US Multi-Society Task Force on Colorectal Cancer. Gastroenterology 2012; 143: $844-857$

[12] Ponugoti PL, Cummings OW, Rex DK. Risk of cancer in small and diminutive colorectal polyps. Digest Liver Dis 2017; 49: $34-37$

[13] Neumann H, Hassan C. Small and diminutive polyps: No cancer, no risk! Digest Liver Dis 2017; 49: 1-2

[14] Vleugels JLA, Greuter MJE, Hazewinkel Y et al. Implementation of an optical diagnosis strategy saves costs and does not impair clinical outcomes of a fecal immunochemical test-based colorectal cancer screening program. Endosc Int Open 2017; 05: E1197-E1207
[15] Hassan C, Pickhardt PJ, Rex DK. A resect and discard strategy would improve cost-effectiveness of colorectal cancer screening. Clin Gastroenterol Hepatol 2010; 8: 865 - 869, 869 e861-863

[16] Kessler WR, Imperiale TF, Klein RW et al. A quantitative assessment of the risks and cost savings of forgoing histologic examination of diminutive polyps. Endosc 2011; 43: 683-691

[17] Rees C], Rajasekhar PT, Wilson A et al. Narrow band imaging optical diagnosis of small colorectal polyps in routine clinical practice: the Detect Inspect Characterise Resect and Discard 2 (DISCARD 2) study. Gut 2017; 66: 887-895

[18] Raghavendra M, Hewett DG, Rex DK. Differentiating adenomas from hyperplastic colorectal polyps: narrow-band imaging can be learned in 20 minutes. Gastrointest Endosc 2010; 72: $572-576$

[19] Kaminski MF, Hassan C, Bisschops R et al. Advanced imaging for detection and differentiation of colorectal neoplasia: European Society of Gastrointestinal Endoscopy (ESGE) Guideline. Endoscopy 2014; 46: $435-449$

[20] NICE. Virtual chromoendoscopy to assess colorectal polyps during colonoscopy. Guidance and guidelines. NICE; 2017: Available from: https://www.nice.org.uk/guidance/dg28 